\title{
IMPLICACIONES INTELECTUALES Y METODOLÓGICAS EN LA SELECCIÓN DE LOS AUTORES Y LA TERMINOLOGÍA TRADUCTORA CASTELLANA DEL SIGLO XV
}

\author{
INTELLECTUAL AND METHODOLOGICAL IMPLICATIONS OF \\ WORDS AND AUTHORS SELECTION IN FIFTEENTH-CENTURY \\ CASTILIAN TRANSLATIONS
}

\author{
SUSANNA ALLÉS TORRENT \\ Columbia University in the City of New York
}

\begin{abstract}
Resumen: Las traducciones constituyeron uno de los canales prioritarios en la recepción del humanismo italiano en la Península Ibérica. A través de esta actividad intelectual, no sólo se recuperó una parte considerable del legado clásico grecolatino, sino que propició un acercamiento a la obra y a las ideas de los autores italianos contemporáneos. Por un lado, el presente trabajo insiste en el papel central de la traducción en el marco de la transferencia cultural entre ambas penínsulas y evidencia el cambio en la selección de los autores traducidos a lo largo del siglo XV; por otro lado, se analizan las implicaciones de dichas elecciones que, además de constituir una transformación a nivel ideológico, supusieron un cambio en la concepción de la actividad de la traducción y en la adopción de una nueva terminología.
\end{abstract}

Palabras clave: recepción humanismo italiano; traducciones castellanas del siglo XV; teoría de la traducción; Alfonso de Palencia; traducir y traducción como neologismos.

\begin{abstract}
Translations were a crucial channel for the reception of Italian $\mathrm{Hu}$ manism in the Iberian Peninsula. This intellectual activity not only led to the recuperation of a significant part of the classical Greco-Roman legacy, but also fomented engagement with the works and ideas of contemporary Italian authors. On the one hand, this article underscores the critical role of translation in cultural transfers between both peninsulas and shows the change in authors selected to translate over the course of fifteenth century. On the other hand, it analyzes the implications of these author selections, arguing that they reveal at once an ideological transformation, a change in the conception of the very act of translation, and the adoption of new terminology.
\end{abstract}

Keywords: reception of Italian Humanism; fifteenth century Spanish translations; translation theory; Alfonso de Palencia; traducir and traducción as neologisms.

\section{SUMARIO}

1. Introducción.- 2. Cambios en la selección de los autores y las obras traducidos en el siglo XV.- 3. ¿Hacia una concepción positiva y humanística de la traducción?- 4. La terminología utilizada: romanzar, trasladar, traduzir.-5. Conclusiones.- 6. Bibliografía citada. 


\section{INTRODUCCIÓN}

A lo largo del siglo XV, las relaciones entre Italia y España, reforzadas desde la llegada de los aragoneses a Nápoles, se intensificaron progresivamente y el número de viajeros hispanos a tierras italianas fue cada vez mayor, bien por motivos conciliares, políticos o de estudio. Síntoma y consecuencia de estos intercambios culturales fueron, por un lado, las traducciones de obras clásicas, de clara influencia humanística; por el otro, de autores italianos.

Múltiples han sido los estudios llevados a cabo en las últimas décadas con el fin de realizar un censo de las traducciones elaboradas en España ${ }^{1}$. Los resultados han permitido constatar una actividad conspicua de traducciones peninsulares tanto de obras clásicas como italianas. Estas traducciones, en tanto que transferencia cultural, son un termómetro, si no el único, sí el más claro, de la vía de comunicación entre ambas culturas.

En el presente trabajo, trazamos, en primer lugar y de una manera general, el panorama de traducciones llevadas a cabo a lo largo del siglo XV con la intención de resaltar el cambio en la selección de los autores traducidos. A continuación, valoramos si la traducción de obras procedentes de tierras italianas implicó a su vez un cambio en la concepción y en el método de traducción. En fin, ponemos de relieve el hecho que estas transformaciones conllevaron la aparición de una nueva terminología para designar la traducción como tal.

\section{CAMBIOS EN LA SELECCIÓN DE LOS AUTORES Y LAS OBRAS TRADUCIDOS EN EL SIGLO XV}

Un rápido recorrido a través de la actividad traductora permite establecer tres grandes etapas, diferenciadas básicamente por la elección de los autores y, sobre todo, por la cantidad de versiones llevadas a efecto: la primera abraza los años crepusculares del Trescientos y el alba del siglo siguiente; el reinado de Juan II de Castilla y los años de la Corona de Aragón en Nápoles constituyen la segunda; y la última arranca de los años sesenta y setenta para llegar hasta los últimos años del Cuatrocientos².

\footnotetext{
${ }^{1}$ Véase, por ejemplo, el ya clásico Beardsley 1970; así como Serés 1997; Conde 2006; Lafarga, Pegenaute 2004; Weiss 2013; los múltiples trabajos de Alvar 2001; Alvar, Lucía 2003; Alvar 2010. Además, siempre indispensables son la base de datos en línea del Proyecto Boscán, y para el catalán, Cabré, Ferrer 2012.

${ }^{2}$ Una periodización paralela es propuesta en Alvar 2010, p. 259. Para una buena visión de conjunto de las traducciones existentes, véanse las tablas número 1-2 en Muñiz 2004, p. 63. 
Dejemos a un lado la primera época durante la cual escasas fueron las traducciones de autores clásicos, entre las cuales recordamos la versión parcial del Ab urbe condita de Tito Livio por Pero López de Ayala, y las versiones de Séneca, Salustio, Valerio Máximo, Vegecio o Paladio, llevadas a cabo en la Corona de Aragón. Mucho más significativos, por constituir un salto cualitativo, fueron los años que sucedieron a la llegada de los catalanes a Nápoles y al reinado de Juan II en cuyo seno operó el círculo del marqués de Santillana.

Hacia los años cuarenta aparecieron ya muestras evidentes por la tradición romance italiana, especialmente por Dante, Petrarca y Boccaccio, que empezaron a leerse desde una óptica diferente. Pero no sólo las tres coronas toscanas captaron la atención de los traductores castellanos, sino que también se empezaron a trasladar los escritos de diversos humanistas italianos. Así, el De infelicitate principum de Poggio Bracciolini fue vertido por Martín de Ávila (1446); Nuño de Guzmán versionó entre 1453 y 1458 la oración dedicada a Pandolfo Malatesta escrita por su amigo Giannozzo Manetti, y sobre todo circularon los escritos de Leonardo Bruni, bien conocido por su correspondencia con los más altos mandatarios de la Península Ibérica y por la disputa mantenida con Cartagena sobre la traducción de Aristóteles. De Bruni interesó no sólo su vertiente histórica y exegética (los comentarios al De bello punico en especial), sino también otros múltiples aspectos tratados en sus epístolas. El Aretino tuvo en territorio peninsular un fuerte papel mediador en algunas traducciones indirectas de autores griegos, como veremos a continuación ${ }^{3}$.

Paulatinamente se incorporaron a lo largo de este período traducciones romances de autores clásicos: los latinos casi siempre en traducciones directas, y los griegos a través de latinizaciones debidas a humanistas italianos. Los escritos de Séneca fueron los más traducidos debido a la cercanía de su filosofía estoica al cristianismo, una labor en la que destacó Alfonso de Cartagena, a quien se deben también la mayoría de las traducciones del otro gran autor talismán, Cicerón: De officis, De senectute, De inventione y Oratio pro Marcello ${ }^{4}$. Las versiones de Virgilio, uno de los autores más estudiados

\footnotetext{
${ }^{3}$ Fueron diversas las obras traducidas de Leonardo Bruni, entre las cuales hallamos: Vite di Dante e del Petrarca; Vita Aristotelis (en traducción castellana anónima, 1450), véase Mazzocchi, Pintacuda 2001, pp. 439-489 y Bartoli 2007, pp. 175-182; el Commentarius de primo bello punico, traducido al catalán por Francesc Alegre, 1472; el Isagogicon moralis diciplinae ad Galeottum Riscasolanum, en dos traducciones castellanas anónimas, una en 1450, otra entre 1450-1458; el De bello italico adversus Gothos (1450); la Novella di Seleuco e Antioco (1450); la Oratio in hypocritas (1450); algunas cartas procedentes de sus Epistolarum libri VIII (VII 2, 6, dirigida al Rey Juan II de Castilla, fechada en 1435-1437; V, 4, a Poggio Bracciolini, del 1450; V, 1, a Ugo Benzi, del año 1450; y la V, 2, dirigida a Tommasso Cambiatori, también del 1450); en fin, el De militia (1435-1450), todas ellas en traducción castellana anónima.

${ }^{4}$ Sobre Alfonso de Cartagena, véase Morrás 1991, 1995.
} 
y leídos ininterrumpidamente durante toda la Edad Media, se limitaron sin embargo a la sola Eneida, vertida por Enrique de Villena entre 1427 y 1428 , también conocido por sus traducciones al catalán y por la traducción del De re militari de Vegecio. Entre los historiadores, Salustio fue trasladado en lengua castellana por Vasco Ramírez de Guzmán (De Coniuratione Catilinae y el De bello Iugurtino). De Valerio Máximo los Dictorum factorumque memorabilium, que contaban sólo con una traducción catalana de Antoni Canals (diciembre 1395), fueron traducidos al castellano por Juan Alfonso de Zamora durante la primera mitad del siglo $\mathrm{XV}^{5}$.

Por lo que se refiere a los autores griegos, el Omero romançado (1442) de Juan de Mena tenía claras raíces medievales y se basó en una edulcorada Ilias latina. El procedimiento habitual en la apropiación de la literatura griega fue, como decimos, el de la traducción indirecta o a partir de versiones latinas llevadas a cabo por humanistas italianos, como Leonardo Bruni, Pier Candido Decembrio o Giovanni Aurispa. Gracias al primero, Pero Díaz de Toledo pudo romancear el Fedón platónico ( $c a$. 1455), mientras que para el pseudo-platónico Axyochus (ca.1455) se sirvió de la traducción latina de Cencio de' Rustici ${ }^{6}$. Decembrio allanó el terreno a Pedro González de Mendoza, hijo del Marqués de Santillana, para traducir algunos cantos de la Ilíada (ca. 1446-1452) ${ }^{7}$; Martín de Ávila llevó a efecto dos versiones que abordaban el debate político sobre César, Aníbal y Escipión, muy en boga en esos años y que había despertado acaloradas discusiones entre Poggio y Guarino: de un lado, la Comparación de Cayo Julio César y Alejandro Magno que Pier Candido Decembrio compuso en italiano a imitación de Plutarco para suplir la synkrisis del original y, del otro, uno de los Diálogos de los muertos de Luciano, traducidos al latín por Giovanni Aurispa, la Contençión entre Alexandre, Anníbal et Scipión ${ }^{8}$.

Pero no será hasta los años sesenta, a lo largo del reinado de los Reyes Católicos, en que se produce una apertura mucho más decisiva en este terreno y, especialmente, en el de los escritos originales de los humanistas italianos. Los discursos de Stefano Porcari fueron así traducidos por un anónimo castellano hacia 1460 y un decenio después aproximadamente otro

\footnotetext{
${ }^{5}$ Esta traducción parece haber sido realizada a partir de la versión de Canals, $c f$. Avenoza 1993, p. 47, n. 4.

${ }^{6}$ González, Saquero 2000, p. 168. Algunos estudiosos han barajado la posibilidad de que Pero Díaz de Toledo no recurriera a versiones intermedias y que sus conocimientos de griego fueran suficientes para llevar a cabo la traducción: Alvar 2010, pp. 245-246 y Díaz de Toledo 1993, pp. $97-110$

${ }^{7}$ Serés 1997.

${ }^{8}$ Bravo 1977, pp. 143-185; Mazzocchi 2007, pp. 183-206; Santoyo 2004, pp. 144 y 147; Alvar 2010, pp. 348-353.
} 
anónimo trasladó al catalán los dos tratadillos eróticos de Leon Battista Alberti, Deiphira y Ecatonfilea; Guarino Veronese interesó sólo por su De linguae latinae differentiis, y Leonardo Bruni tuvo una versión catalana del Commentarius de primo bello punico gracias a Francesc Alegre (1470-72), mientras que el Isagogicon moralis disciplinae ad Galeottum Riscasolanum llegó a las prensas en traducción anónima castellana (1496) ${ }^{9}$; de Antonio Beccadelli, Jordi de Centelles vertió al catalán De dictis et factis Alphonsi regis Aragonum et Neapoli por motivos de oportunidad política (1481-1484); y respondió al gusto por las novelle la traducción castellana anónima de la Historia de duobus amantibus de Enea Silvio Piccolomini (1496) ${ }^{10}$.

En cuanto a los autores latinos, las Heroidas ovidianas fueron vertidas al castellano por Jorge Rodríguez de Padrón ( $c a$. 1450), mientras que las Metamorfosis fueron traducidas al catalán por Francesc Alegre ${ }^{11}$. Por lo demás, el listado permanece dentro de los cánones habituales: Cicerón, Virgilio, Boecio, Valerio Máximo y los Dísticos de Catón.

Pero quizás la aportación más relevante en el panorama de las traducciones fue el de la literatura griega clásica. En cuanto a las obras filosóficas, la Ética de Aristóteles vertida por Bruni fue puesta en castellano por Carlos, príncipe de Viana, juntamente con la Política y la Economia (titulada La Philosophia moral del Aristotel: es a saber Ethicas: Polithicas y Economicas: en Romançe); también el catalán vio una traducción de la pseudo-aristotélica Economia a manos de Martí de Viciana; y parece que Nuño de Guzmán romanceó la Ethica de Aristóteles a partir de una traducción catalana anónima (ant. 1467), dependiente de la versión de Bruni ${ }^{12}$. A estas deben sumarse otras dos aportaciones remarcables: otro romanceamiento del príncipe de Viana del tratado pseudoplutarqueo sobre la nobleza (De toda la condición de la noble$z a)$ a partir de la versión latina de Angelo Decembrio y una traducción anónima de las fábulas de Esopo, titulada Esopete ystoriado (1482).

Los datos indican un aumento del interés especialmente en lo que atañe a las obras historiográficas. En este sentido, uno de los traductores de la época más prolíficos fue, sin duda, Alfonso de Palencia, cuya aportación amplió considerablemente el panorama hispánico de traducciones. A parte de su versión del Specchio della Croce de Domenico Cavalca, el grueso de su aportación a la historia de las traducciones españolas se concentra en la historiografía griega de época romana. De Plutarco, eligió las Vidas paralelas,

\footnotetext{
${ }^{9}$ Véase Jiménez 2010.

${ }^{10}$ Piccolomini 2003; del futuro papa también se tradujeron al castellano otras obras, como la Epístola al Gran Turco por Fernando de Córdoba, algo después del 1481.

${ }^{11}$ Pujol 2012.

${ }^{12}$ Alvar 2010, p. 27; Cabré, Ferrer 2012, p. 48.
} 
perfectamente acordes con su sed de erudición histórica. De Flavio Josefo tradujo el Contra Apionem y las Antiquitates judaicae (93-94 d. C.), traducidas con anterioridad sólo al catalán con el título de Llibre de les antiguitats judaiques por un anónimo, antes de $1408^{13}$.

Pero a estos trabajos deben añadirse, además, un grupo de traducciones que Palencia trasladó, probablemente durante los años ochenta, por un mero azar, pues todas ellas se hallaban en la edición de las Vidas paralelas (Plutarco 1478) que utilizó para llevar a cabo su traducción ${ }^{14}$. Dicha edición contenía un grupo de biografías auténticas de humanistas italianos, otras traducciones realizadas del griego al latín y, en fin, una obra de historiografía romana. Todos estos trabajos ensanchan de manera considerable el panorama traductor peninsular castellano. En primer lugar, Palencia llevó a cabo dos opúsculos que carecen de cualquier otra traducción ni en castellano ni en catalán; se trata, por un lado, de la Vida de Pomponio Ático escrita por Cornelio Nepote y, por el otro, el Breviario de historia romana de Rufo, obras escolásticas, la última de las cuales debió de interesar a Palencia por su análisis histórico. Asimismo, trasladó una serie de biografías humanísticas que acompañaban a las de Plutarco: la Vita Aristotelis y el Cicero Novus de Leonardo Bruni, la Vita Platonis de Guarino y las tres biografías compuestas por Donato Acciaiuoli: las Vitae Hannibalis et Scipionis y Vita Caroli Magni. Obras escritas en un latín que no era fruto de una traducción, con la pérdida de espontaneidad que ello suponía, sino expresión libre de los modernos émulos de Cicerón. Por último, Palencia tradujo tres obras helénicas más, también presentes en su ejemplar latino: el Evágoras de Isócrates, traducido del griego al latín por Guarino veronés, una Vida de Homero atribuida falsamente a Plutarco y traducida por el florentino Pellegrino degli Agli, y la biografía de Agesilao debida a Jenofonte y traducida por Battista Guarini ${ }^{15}$.

El problema que plantean estas traducciones es la mayor o menor intencionalidad y consciencia con que Palencia las llevó a cabo. En algunos casos Palencia creía estar traduciendo obras originales de Plutarco, y así se confirma en los títulos que anteceden las obras del Agesilao de Jenofonte, que sustituía a la biografía auténtica plutarquea y se situaba con su paralelo, Pompeyo; el Evágoras de Isócrates tampoco pareció despertarle grandes dudas, como tampoco lo hizo la vida de Homero del Pseudo-Plutarco. Sí tuvo, en cambio, algún titubeo con la vida de Pomponio Ático donde parece sugerir una historia algo rocambolesca: Plutarco habría encontrado la vida de Ático

${ }^{13}$ Cabré, Ferrer 2012, p. 79.

${ }^{14}$ Para los detalles sobre esta traducción, véase: Allés 2008.

${ }^{15}$ Algunos trabajos sobre estas traducciones son: Allés 2010, 2013, 2014a, 2014b. 
escrita en latín por Cornelio Nepote y la habría traducido al griego ${ }^{16}$. La hipótesis, en todo caso, no pareció convencer a Palencia, pues demuestra saber que Nepote era amigo de Cicerón y, por tanto, anterior en el tiempo a Plutarco. Muy diferentes fueron los casos de las biografías de Platón, Aristóteles y Carlomagno, y del Breviario de historia romana de Rufo. En todos estos casos, Palencia aclara abiertamente que se trata de obras compuestas por humanistas italianos en los tres primeros casos, y por un historiador de época romana en el último. En cambio, parece que Palencia no sospechó que las vidas de Aníbal y Escipión, camufladas entre las vidas paralelas de Pelópidas y Marcelo, y Filopemen y Tito Flaminio, no eran de Plutarco sino de su conocido Donato Acciaiuoli. Un error que sorprende ante sus vastos conocimientos de historia. Esta última serie de autores y traducciones bien merecerían ulteriores estudios, como podría ser el caso de Nepote, pues abren nuevos senderos de investigación en la fortuna y recepción de ciertos autores clásicos en la Península Ibérica, aunque sea de una manera indirecta. Por otra parte, las biografías humanísticas escritas por Bruni, Guarino y Acciaiuoli, además de recuperar los modelos clásicos del género biográfico, tan en boga en la Italia del Cuatrocientos, ensanchan la galería de humanistas italianos traducidos en tierras ibéricas.

\section{3. ¿HACIA UNA CONCEPCIÓN POSITIVA Y HUMANÍSTICA DE LA TRADUCCIÓN?}

Conviene ahora plantearse si estas versiones de autores clásicos, procedentes de la labor humanística, y de obras de autores italianos supusieron también un cambio en el método de traducción o en la concepción sobre la traducción.

Como es sabido, la reflexión metodológica sobre la historia de la traducción o, mejor dicho, sobre la reflexión del método de traducción no cuajó en ningún tipo de tratado u obra a lo largo de la baja Edad Media. No fue hasta inicios del siglo XV en que autores como Leonardo Bruni cambiaron este panorama caracterizado por la ausencia de una "literatura crítica"17. Aun así, prólogos, proemios, cartas dedicatorias, epílogos y otros paratextos que acompañaban a las propias traducciones ofrecen -como es sabido- un mate-

\footnotetext{
${ }^{16}$ Esta es la rúbrica que antecede la traducción de Cornelio Nepote: "Plutarcho philósopho escrivió en Griego la vida de Pomponio Attico varón ylustre. Et segund pareçe fallola escripta en latín por Cornelio Nepote pariente de Ciçerón que fue antes mucho que Plutarcho. y el Cronista Alfonso de Palençia: la traduxo en romançe Castellano" (Plutarco 1491, II, f. 318).

${ }^{17}$ Me refiero al De recta interpretatione; una edición, de entre las múltiples que existen, acompañada de traducción es: Bruni 2004.
} 
rial precioso que permite reconstruir ideas, opiniones, gustos y tendencias en el quehacer traductológico de los intérpretes de la época. La Península Ibérica no fue una excepción y, en consecuencia, la valoración del grado de innovación o continuidad de la práctica y la teoría traductora no puede llevarse a cabo si no es rastreando algunas pistas en sus prólogos y, sobre todo, a través de un análisis minucioso de su práctica traductora, considerando sus conocimientos en la lengua de partida y en la de llegada ${ }^{18}$.

La influencia de la figura de Leonardo Bruni en tierras peninsulares ha sido ampliamente estudiada, así como su faceta de traductor. El alcance de sus ideas fue tal que incluso a veces el grado de modernidad de los autores hispánicos, y no sólo, puede medirse, en cierta manera, a través de un acercamiento a las ideas brunianas. A él se deben algunas versiones de las Vidas paralelas de Plutarco, además de otros autores como San Basilio Magno (Oratio ad adolescentes), diversos diálogos platónicos (Fedón, Fedro, Apología de Sócrates) u obras de Aristóteles (Etica Nicomaquea, Política). A diferencia de otros humanistas, Leonardo llegó a dominar tanto el vulgar como el latín y el griego; no sólo eso, sino que fue el primero en teorizar sobre el método de traducción en su De interpretatione recta, compuesto entre 1424 y 1426. Una serie de ideas que nacían de su experiencia como traductor, prolongada a lo largo de toda su vida y espoleada por la polémica contra prácticas medievales ${ }^{19}$. Así, hacia los años 20 , a raíz del debate desatado por su nueva traducción de la Éthica a Nicomaco de Aristóteles, decide defender su método fijando sus rasgos distintivos de forma ordenada. Allí, Bruni se aparta de la terminología usada hasta el momento, al haber perdido ya la razón de ser la antítesis frontal ad verbum y ad sensum. Sitúa, eso sí, en primer lugar y como condición sine qua non, la estricta fidelidad al texto, pero en un sentido más complejo y profundo. Además, enuncia las dotes que debe poseer el traductor y fija con mayor exactitud el método a seguir. Las cualidades del buen traductor, según Bruni, consistirán en el dominio de la lengua y la cultura de partida, para poder captar todas las sutilezas, la fuerza y los significados de las palabras y los conceptos; un conocimiento que procede de la lectura directa de los autores clásicos. El intérprete, además, debe poseer un conocimiento profundo de la lengua y la cultura de llegada para saber en cada momento el valor exacto de los términos equivalentes sin tener que recurrir a préstamos innecesarios. A ello, se sumará el dominio del estilo característico de los mejores escritores, imitándolo y rehuyendo los neologismos y los barbarismos, además de una

\footnotetext{
${ }_{18}$ Véase sobre este tipo de paratextos el estudio recientemente publicado por González, López 2014.

${ }^{19}$ Véase la introducción de P. Viti, en Bruni 2004, en concreto, p. 14, n. 32, así como Botley 2004, pp. 5-62.
} 
fina sensibilidad para captar la elegancia y la armonía del original, es decir, el ornatus, además de la doctrina. Dos capacidades más, en fin, constituyen el método para traducir correctamente, esto es, la de saber captar la singularidad de la lengua y la voluntad del escritor y la de preservar la armonía y el ritmo del texto original, conservando los contenidos y la belleza del estilo, pero renunciando, si es preciso, a algunas figuras retóricas. El principio básico de toda su teoría es la necesidad del dominio de la cultura de partida y el profundo conocimiento de ambas lenguas, la de partida y la de llegada; una condición que no podían cumplir todos los traductores de la época, especialmente en el terreno de la literatura clásica.

Fueron, pues, estas ideas de Bruni las que tuvieron mayor peso en el Humanismo y a ellas se remitieron gran cantidad de traductores, que acabaron por desechar prácticas precedentes.

A falta, pues, de obras cardinales en la Península Ibérica como el tratado de Bruni, debemos remitirnos a una serie de textos que, de alguna manera, ponen de manifiesto la existencia de una reflexión en la línea de las concepciones humanísticas italianas ${ }^{20}$. Por lo que se refiere al siglo XV los estudiosos coinciden en señalar al menos tres autores clave: Alfonso de Cartagena, Alfonso Fernández del Madrigal, el Tostado y Pedro Díaz de Toledo. Se recuerdan también las posturas adoptadas por Juan de Mena, Antón Zorita, Pedro de Chinchilla, Íñigo López de Mendoza, Pedro González de Mendoza y Carlos, príncipe de Viana. Evidentemente la lista se podría alargar, dada la frecuencia con que los traductores incluían en sus prólogos alguna reflexión al respecto, que acercaba a algunos a una aptitud más bien heredada de una concepción medieval y a otros, en cambio, a las nuevas corrientes procedentes de Italia. Veamos algunos casos.

Alfonso de Cartagena había traducido a Cicerón y a Séneca, además de concluir en 1422 la versión del De casibus de Boccaccio ${ }^{21}$ dejada incompleta por López de Ayala. Son diversas las sedes donde Cartagena habla de la traducción, pero sus ideas principales se condensan en el prólogo a su versión

\footnotetext{
${ }^{20}$ Son muchos los trabajos sobre la historia de la traducción en la Península Ibérica: Rusell 1985; García 1994; Hurtado 2007; los trabajos de Santoyo 1987, 2008, 2009; Lafarga, Pegenatute 2004, pp. 21-208; de particular interés para el siglo XV es la antología de textos en Cartagena 2009.

${ }^{21}$ Cartagena llevó a cabo un gran número de traducciones: de Cicerón tradujo De officis, De senectute, Retórica vieja (o sea el De inventione), concluida hacia 1422; De Boccaccio trasladó la Caída de príncipes, que había sido iniciada por Pero López de Ayala; Séneca, sin duda, fue el autor más traducido: De vita beata, De septem artibus liberalibus, De documentis et doctrinis, De providentia Dei, I; De providentia Dei, II; De clementia I y II; De fortuitis; De remediis fortuitorum; De bello (sentencias de Séneca padre e hijo), a ellos se suman dos tratados de Marco Anneo Séneca, erróneamente atribuidos a su hijo Lucio Anneo Séneca.
} 
del De inventione de Cicerón, titulada De la Retórica (ca. 1430)22. Allí Cartagena inaugura su discurso aludiendo a los trabajos clásicos en el terreno de la retórica y la elocuencia. Por un lado, hay autores que escribieron según los preceptos del arte, como Demóstenes y Esquines entre los griegos, o Salustio y Cicerón entre los latinos; precisamente los dos oradores griegos que había traducido Cicerón y, por emulación suya, muchos humanistas, incluidos Bruni y Jorge de Trebisonda. A continuación, Cartagena cita a autores que escribieron sobre la retórica, ca una cosa es fablar según la arte, et otra es fablar de la arte; en este caso, como cabía esperar, Aristóteles cubre la parcela griega, y Cicerón la latina. Llegado a este punto, Cartagena afirma profesar las ideas de San Jerónimo: de un lado, están los libros de la Sacra Scriptura, en que es error añadir o menguar, así como también doctrinas que (...) tienen el valor por la autoridad de quien las dixo y poseen un significado moral o místico, obras que hacen necesario exprimir una palabra por otra. Por otro lado, están las obras en las que se cata lo que la simple letra significa, y para con las cuales el objetivo del traductor es retornar la intención de la escritura en el modo del fablar que a la lengua en que se pasa conviene, a fin de que más sin trabajo lo pueda entender quien leer la quisiere, es decir con preeminencia del respeto a la lengua de destino, el querer decir, no el decir del texto original ${ }^{23}$. En este sentido, Baldissera adscribe a Cartagena entre aquellos que traducían ad sententiam, según los preceptos de Crisoloras, tal y como explica Cencio de'Rustici, y sitúa críticamente su labor en una línea que hoy consideraríamos de traducción libre, aunque siempre atenta al significado último del texto ${ }^{24}$.

Nuestro autor es consciente de que toda traducción presentará algunas palabras mudadas de su propia significación e algunas añadidas, pero este es un riesgo inevitable que debe asumirse, especialmente si se trata de un texto profano. Su idea de fondo es guardar (...) la intención, aunque la propiedad de las palabras se mude, porque con el método "ad verbum" necesario es que la escriptura sea obscura et pierda gran parte del dulzor. Cartagena, como Bruni, exigía, en fin, al traductor y al lector una buena preparación en la materia sobre la que versa la obra: las composiciones que son de ciencia o de arte liberal, para bien se entender, todavía piden estudio. Pero se diferenciaba del italiano en su rechazo de la subordinación del texto a la elocuencia, incluidos los textos procedentes de la disciplina moral. En los textos científicos de-

${ }^{22}$ Una versión del texto se encuentra en Cartagena 2009, pp. 42-44.

${ }^{23}$ Véase para la interpretación de sus palabras: Vega 1994, p. 64.

${ }^{24}$ Cartagena 2003, p. 33. El texto sobre los principios de traducción de Crisoloras descritos por Cencio de'Rustici se encuentra en: Bertalot 1929-1930,pp. 210 y ss.; otros trabajos clásicos sobre el método de los humanistas son: Rossi 1992, pp. 94-95 y p. 153 bajo el epígrafe Criteri dei traduttori; Cammelli 1941, vol. I, pp. 90 y ss.; Sabbadini 1920, pp. 23-24. 
bía primar ante todo la claridad y nunca la elocuencia, pues ésta, a menudo, en lugar de facilitar la comprensión, la oscurecía detrás de una retórica vacua ${ }^{25}$.

Por otro lado, Alfonso del Madrigal también llevó a cabo algunas traducciones entre las que destaca el romanceamiento, elaborado hacia 1445 , de la Crónica Universal de Eusebio de Cesarea, que había sido traducida al latín por San Jerónimo ${ }^{26}$. En el prólogo, el Tostado exponía algunos de sus principios. Las traducciones -explica- presentan múltiples dificultades, básicamente por dos motivos: por un lado, tanto el griego como el latín tienen una gran riqueza de vocabulario y recursos para crear nuevos derivados; en cambio la lengua romance no. Por el otro, tanto el griego como el latín disponen de recursos retóricos y estilísticos elaborados, mientras que el vulgar carece aún de ellos. Ponía, en definitiva, de relieve el desigual desarrollo de las lenguas como obstáculo para su plena correspondencia. El Tostado concluye apelando a una traducción que respete el espíritu del texto, en detrimento de una traducción literal:

Por lo qual toda translation de latín en vulgar para se fazer pura et perfectamente es dificile si se faze por manera de interpretación / que es palabra por palabra et non por manera de glosa la qual es absuelta et libre de muchas gravedades. trasladar):

Había, pues, dos tipos de traducción (son dos las maneras de una es de palabra a palabra / et llamase interpretación; otra es poniendo la sentencia sin seguir las palabras, la qual se faze comunmente por unas luengas palabras, et esta se llama exposición o comento o glosa.

En el primer caso, es de más autoridad y non se añade et por ende siempre es de aquel que la primero fabricó. En el segundo, es más clara para los menores ingenios y se fazen muchas adiciones e emendamientos por lo qual non es la obra del autor mas del glosador.

El Tostado considera en definitiva que el método literal es el de más peso, especialmente en los textos filosóficos, donde proponía situar los comen-

\footnotetext{
${ }^{25}$ Alfonso de Cartagena había abordado el mismo tema en sus Declinationes super noua quadam Ethicorum Aristotelis translatione de 1431 y es uno de los Leitmotiven de la Problematice Aristotelis philosophie protectio y Comparatio philosophorum Platonis et Aristotelis, trabajos ambos de Trebisonda. Véase a tal propósito: González, Moreno, Saquero 2000, p. 233; Palencia 1998, p. XXXIX; Lawrance 1990, pp. 223-224.

${ }^{26}$ Sobre la traducción y Alfonso el Tostado, véase: Wittlin 1998; Recio 1991, 1995. El texto del prólogo se encuentra en Cartagena 2009, pp. 96-98.
} 
tarios a modo de notas marginales y recordaba los trabajos de Boecio, gran defensor del método ad verbum. Aunque en la línea jeronimiana, la traducción propiamente dicha, llamada por el Tostado interpetación, debía reproducir en el fondo el pensamiento y los conceptos del autor originario, sin añadir nada de personal. La distinción neta entre traducción y glosa desdoblaba al traductor convertido, por un lado, en mero vehículo de la obra original, por el otro, en glosador ${ }^{27}$.

Casos como los de Cartagena y el Tostado indican todavía una concepción traductológica algo anclada en las ideas y distinciones medievales $\mathrm{y}$, en especial modo, a las ideas de matriz jeronimianas. Reflexiones sobre el desigual desarrollo de la lengua vulgar, la distinción de acercamiento al texto según la materia tratada o distinciones basadas en polaridades ya conocidas (traducción literal versus traducción libre), quedan lejos de la profundidad metodológica propuesta por Bruni. Aun así, su práctica indica por lo general una nueva sensibilidad mucho más cuidadosa con el instrumento lingüístico.

Valdrá la pena ahora llamar la atención sobre un autor ya mencionado, Alfonso de Palencia, porque su figura conjuga elementos tradicionales con otros más en consonancia con las corrientes humanísticas. Cabe recordar, de hecho, que su atracción por los humanistas le hizo abordar casi todos los géneros por ellos cultivados: la historia, la lexicografía, la traducción de los clásicos. Pero Palencia tampoco elaboró teoría alguna, ni se manifestó expresamente sobre el método por él empleado, a pesar de sus múltiples traducciones del latín al castellano. Nuestra fuente de información se limita una vez más, por tanto, a observaciones dispersas en los prólogos de sus trabajos, y al análisis de su práctica traductora.

En una primera época, Palencia llevó a cabo una serie de autotraducciones de obras por él compuestas en latín y después romanceadas en caste1 lano ${ }^{28}$, así como una versión castellana del Spechio della Croce de Domenico Cavalca, escrita en italiano ${ }^{29}$. A una segunda época pertenecen las traducciones de autores clásicos.

\footnotetext{
${ }^{27}$ A este respecto son interesantes las palabras de Carlos de Viana al prólogo de la Ética de Aristóteles (1455): "Ca dize sant Hieronimo en la epistola del muy buen stilo de interpretar: y yo por cierto no somamente vso mas de la libre voz me aprouecho enla interpretacion de las Griegas y santas scripturas: donde el orden es misterio d'las p[a]labras: no solamente la palabra d'la palabra: mas del seso la sentencia exprimir. Y quasi esto dixe Tullio en los traslados que fizo del Prothagoras de Platon: y dela Yconomica de Xenofonte: y de las dos oraciones de Schinio y Demostenes. Item Terencio: Platon: y Cecilio: y Oracio en su poesia: a los quales seguiendo quise assi mi presente traducion fazer" (Cartagena 2009, p. 217).

${ }^{28}$ Sobre la autotraducción durante el siglo XV, véase Alvar 2010, pp. 248-249 y Cátedra 1991.

${ }^{29}$ Una edición moderna se encuentra en: Palencia 1996b.
} 
En el proemio a la primera autotraducción, concluida en 1457, de la Batalla campal entre lobos y perros, Palencia trata varios puntos interesantes dirigiéndose a Alfonso de Herrera:

Et comoquiera que mucho se me faga grave el romançar sabiendo las faltas que así en el son de las cláusulas como en la verdadera significaçion de muchos vocablos de neçesario vienen en las translaçiones de una lengua a otra, mayormente en lo que de latín a nuestro corto fablar se convierte (...). Et aun si en mí tanta parte no ovieras con tu virtud aquistado, fazías más fuerte tu ruego con una razón legítima bastada de fuerças poniendo delante cuánto mayor fruto traería el trabajo de la conpusiçión si viniese en conosçimiento de todos que non si entendida de pocos fuese ajena a los más de los nobles d'esta nuestra provincia, a los cuales más perteneçe saber y más deve deleitar la materia en este tratado so manera de fablas contenida (Martín 2013, p. 97).

Dejando a un lado el tópico de la dificultad aducida como captatio benevolentia, la cuestión de fondo planteada por Palencia nos lleva a la ya mencionada cuestión de la asimetría en la correspondencia interlingüística, es decir, al diferente desarrollo del latín y la lengua vulgar. Pero resuena también en sus palabras la doble preocupación de Bruni por las clausulas $^{30}$ y la verdadera significación de muchos vocablos, o sea por la dificultad de reproducir el ritmo del original, y la fuerza y el significado de las palabras, tanto que el traductor era invitado a saber comprender en profundidad las implicaciones de un vocablo para poder encontrar el equivalente justo. Como buen lexicógrafo, nuestro autor no podía no tener una acusada sensibilidad ante este problema.

El prólogo de Palencia plantea asimismo la utilidad de la traducción para alcanzar el número más amplio posible de lectores y poder así aleccionarlos. Consciente de la poca difusión que garantizaba el latín fuera de un selecto ambiente, parece recordar el aserto de Dante: Chè dare a uno e giovare a uno è bene; ma dare a molti e giovare a molti è pronto bene ${ }^{31}$. Por lo demás, la utilidad de su obra es uno de los motivos recurrentes, que lo acerca al espíritu educativo del humanismo cívico más que al erudito.

En aparente contraposición con este deseo divulgador, el prólogo sostiene luego la casi imposibilidad de una traducción que no deforme y envilezca el original:

${ }^{30}$ En el Universal Vocabulario Palencia da dos definiciones de cláusula: de una parte, "Clausula: la que los griegos llaman periodo segund Festo Pompeyo es llamada por conclusión breve", de la otra, "Clausula: en las oraçiones sentençia breve assi como en el epodo que es final recollection" (Palencia 1967, I, f. 80r).

${ }^{31}$ Dante, Convivio, VIII, 3, muchas de cuyas ideas son de inspiración aristotélica (Eticas I, cap. 1). 
Et assí mesmo diome osadía para que sin reçelo de mucha reprehensión tomase este cargo que tengo de romançar lo que yo mesmo conpuse. Ca si tratado por otro conpuesto oviera de vulgarizar, primero te rogara que non me mandasses cosa en que fuese con razón después de los varones letrados reprehendido, ni creo que tú insistieras en lo que reprehensión me pudiera traer. Pues lo uno y lo otro entra so la ley de verdadera amistad, espeçialmente si junto con mi escusaçión te diera a entrender los muchos denuestos que incurren aquellos que luego se atreven a trapasar de lengua limada latina a nuestro corto vulgar muchas escripturas que no pueden ser trasladadas por alguno, aunque mucho enseñado sea, sin perder la graçia y todo el son y el fruto de la conpusiçión y la mayor parte del verdadero significado, en tal manera que lo agudo se torna grosero y lo muy bivo se amorteçe del todo y lo que primero tenía calor y fuerças así se resfría y enflaqueze que allende de la injuria fecha a los altos conponedores valdría más nunca leerse, pues no alcançando el conoçimiento del dulçor frutuoso con fiuza de fallar todos los libros en lengua vulgar desdeñan aprender la latina, donde muchos y mayores daños proçeden de los que en este prólogo breve dezirte podría y tales que no poco valdría con la péñola quien devidamente en çient fojas de grand conpás las reduxese y bien recontase (Martín 2013, pp. 97-98).

Ello ha llevado a más de un crítico a clasificar a Palencia como mero partidario de la intraducibilidad ${ }^{32}$; sin embargo, los límites del traslado a los que alude el Prólogo se refieren al distinto grado de perfeccionamiento de las lenguas: ricas y limadas las clásicas, toscas y pobres las romances ${ }^{33}$. No sólo eso, sino que distingue implícitamente entre textos más y menos traducibles cuando critica a aquellos que, ignorando la dificultad, han ofrecido una caricatura de la obra vertida. No se trata de malos traductores, sino de textos que por su refinamiento sobrepasan las posibilidades de la lengua vulgar. Nos hallamos, pues, ante las mismas objeciones de Cartagena y el Tostado. De paso, Palencia señala los elementos representativos de la textualidad literaria: la graçia, el son, el fruto de la composición y el significado, aquí sí, emerge tímidamente la dimensión retórica de la traducción individualizada por el mismo Bruni.

Su espíritu humanístico privilegiaba la lengua latina por encima de la castellana, que limitaba a una función divulgadora. En éste y en el prólogo que comentaré a continuación, Palencia insiste en la necesidad de acceder al original latino y lamenta que los nobles, encontrando las obras ya traducidas al castellano, no se preocupen por aprender el latín.

\footnotetext{
${ }^{32}$ Sus palabras han llegado a considerarse "un ataque furibondo contra 'el romanzar', actividad que él emprende casi contra su voluntad" (Morales 2000, p. 123); de la misma opinión es Ruiz 2000,p. 74.

${ }^{33}$ Rusell 1985, pp. 29-30.
} 
Unos años más tarde, en su otra autotraducción, la Perfeçion del Triunfo (1459), al explicar por qué ha dedicado la versión latina de la obra, el De perfectione militaris, a Alfonso Carrillo, arzobispo de Toledo, justifica la elección del destinatario para su versión romance, abundando en la utilidad del romanceamiento para la divulgación, pero resalta a la vez la oportunidad de un cotejo con el original latino, en una implícita negación del valor autónomo del texto traducido ni siquiera desde el punto de vista del lector:

Considerando muchas vezes, muy noble y religioso señor, las dificultades del bien romançar la lengua latina, propuse repremir la mano y no presumir lo que non pode careçer de reprehensión. Pero como ove conpuesto el pequeño tratado de los lobos y perros y que la inteligençia que dél se podía aver conforme a las turbaçiones deste lloroso tiempo sería a pocos manifiesta no se trasladando en vulgar, parecióme devido alterar el propósito y antes escoger que fuese reprehendido iusta o iniustamente de impropiedad en alguna parte de la traslaçión, que dexar sepultado mi trabaio y intençión avida en la conpusiçión de aquella fablilla (...). Et assimesmo fueme visto más razonable dirigirlo a Señor en quien nobleza y conosçimiento de latinidad, y amor de virtudes, y enemistad de los viçios, y enseñança militar concurriesen; y assí lo dirigí al reverendissimo señor Don Alfonso Carrillo, arçobispo de Toledo, primado de las Españas.

Et después, viendo que sy no se vulgarizase vendría en conoçimiento de pocos, lo qual repugnava a mi deseo, antes cobdiçiava que muchos viesen cómo muchos erravan, y lo que trae grandes daños por no emendar, pudiese reçebir emienda por se notificar; estove algún tanto deliberando en cúyo nombre podía más dignamente vulgarizarlo, y a la fin fue acordado que a tu señoría se devía intitular por muchas razones. Porque tomarías gusto de la latinidad y iuzgarías sy en algo se desviava la traslaçión vulgar del enxemplar latino, y por conosçer que favoreçes syngularmente estos tales exerçiçios estudiosos; y conosçerás quánto me movió razón a la aspereza del reprehender la negligençia y poca enseñança de lo tanto conplidero; y más animosamente me defenderás de soberviosas menazas sy algunas iniustamente se fizieren (Palencia 1996a, pp. 129-130).

Palencia pretende, además, que los lectores, como Fernando de Guzmán, tomen gusto de la latinidad. Ello nos hace plantear si concebía sus traducciones en romance como un punto de apoyo para la lectura del texto latino y no sólo como vía de transmisión de ideas útiles al vulgo. La obra "auténtica" había sido redactada en latín y a ella había que remitirse. Para ambos lectores, el que sabía latín y el que lo ignoraba, se presentaban atractivos diferentes: a los primeros se les ofrecía una lección moral, además de un instrumento para el aprendizaje de la lengua latina, en consonancia con la vocación lexicográfi- 
ca y didáctica palenciana. A los segundos, se les ofrecía el reto de cotejar los dos textos a fin de comprobar la mayor o menor fidelidad de la versión.

En cambio, cuatro décadas más tarde, en el prólogo a su traducción de las Vidas paralelas de Plutarco, se percibe una actitud mucho más positiva frente a la traducción que parece responder a una nueva sensibilidad. Se trataba en esta ocasión de trasladar al romance castellano textos latinos traducidos o compuestos por notables humanistas italianos. Por entonces ya la traducción, especialmente del griego al latín, se había convertido en una actividad dignificante para cualquier humanista que se preciase de serlo. Palencia pretende inscribirse en esta corriente, pero ante la imposibilidad de traducir del griego, hace lo que ya otros en los reinos de Castilla y Aragón venían haciendo: recurrir a la traducción indirecta.

En su prólogo, Palencia aclara ante todo que la iniciativa de divulgar las biografías plutarqueas procede de los doctos italianos, casi proponiéndose como un continuador de esa empresa. Unas líneas más abajo, señala que la difusión de la obra se ha producido no sólo en Italia (tanto en latín, como en toscano), sino también en otros países europeos. De ahí su deseo de que las Españas no queden excluidas de la prestigiosa corriente:

\begin{abstract}
Assí que los buenos latinos ytalianos, no solamente preçiaron mucho que d'estas translaciones tan provechosas podiessen ellos gozar, mas aún las trasladaron en lengua toscana por comunicar tan solene escriptura a toda la naçión ytálica. No menos los françeses y alemanes e ingleses y ungaros, gentes belicosas y ganosas de participar de tan alto conosçimiento de las soberanas proezas de los antiguos, dieron obra a la communicaçión d'estas vidas historiales transladándolas cada una de estas gentes en su lenguaje. Lo qual no es menos necessario a los nobles varones de las Españas, que por tener nuestra lengua y vocablos tanta çercanía con la examinada latinidad, se descuydan de ella, donde les recreçen no pequeñas faltas de lo que para el saber mucho les aprovecharía (Plutarco 1491, f. 4r)
\end{abstract}

Cabe señalar el cambio de términos empleados para designar la lengua castellana. Si en 1457 era nuestro corto fablar, aquí Palencia afirma que nuestra lengua posee vocablos muy próximos a la examinada latinidad, cuyo estudio recomienda a los nobles, se supone para que enriquezcan a su vez el propio idioma.

En la misma línea, en el prólogo a su última traducción, la del De bello judaico y Contra Apión gramático (1492) de Flavio Josefo, hallamos también alguna información interesante. El tono es muy similar al utilizado en el prólogo a Plutarco, aunque aquí el excursus dedicado a las hazañas contra los moros de la reina Isabel y su acalorado elogio ocupan prácticamente la 
totalidad. Aun así, destacan algunos datos relevantes. Por un lado, se confirma que la traducción de las Vidas paralelas de Plutarco había tenido una buena acogida:

Avrá sabido vuestra alteza la diligencia que puse en la tradución de las Vidas de Plutarco de latín en romance creyendo (sin me engañar en ello) ser aquella translación por muchas razones muy necessaria a vuestros reynos e a otros muchos naturales vassallos de vuestra real corona (Josefo 1492, f. 2r)

Por otro, la preferencia de Palencia por la traducción de Rufino a la de san Ambrosio a causa de su facilidad pone de manifiesto su postura en favor de una traducción oratoria que, situándose desde la perspectiva del receptor, vehicule los contenidos de la manera más eficaz y agradable posible:

Pero quando ya pareció al bienaventurado santo Ambrosio doctor canonizado e solemnizado por la yglesia cathólica e al muy docto presbytero Ruffino Patriarcha de Aquileya su contemporáneo que cumplía traduzirse aquellas obras de Josepho en lengua latina, cada uno dellos de por sí emprendió la translación por entero. E siendo ambas muy buenas e aprobadas, ovo muchos que se agradassen más de la de Ruffino por la facilidad (...).

Assí mesmo de los bien merecidos loores del clarissimo historiador Josepho, en este prohemio sería demasía dezir más de lo que su mesma historia pronuncia a ver en ella de ornato, e de auctoridad: e de sentencias: e de provechosa doctrina (Josefo 1492, f. 2r).

Son las cualidades del autor que motivan al traductor y deben ser tomadas en consideración: el ornato, es decir, el estilo, según los preceptos de la oratoria y la retórica clásicas, la auctoridad o el reconocido prestigio del autor por deberse a la verdad y a la narración de los hechos verdaderos; y aún más, las sentencias y la provechosa doctrina, en definitiva, el propósito didáctico y formativo de las lecturas.

Los prólogos a Plutarco y a Josefo, especialmente el primero, apuntan, en suma, a un cambio de perspectiva, que lleva a valorar la traducción de modo más positivo y complejo, aunque sin lograr acercarse ni de lejos al nivel de problematización de un Bruni. Puede observarse una progresiva maduración que parte de una concepción subsidiaria e instrumental del romanceamiento, como obra menor a causa del corto vulgar castellano enfrente de una limada lengua latina, para llegar, con las traducciones de Plutarco y Josefo, a una concepción mucho más positiva y propositiva del propio trabajo y a una mayor confianza en el propio instrumento lingüístico. Además, se reafirma la idea de la utilidad de la traducción, que permite acercarse a la gran cultura antigua incluso a aquellos que desconozcan el latín. 
Su vocación didáctica y el anhelo por acceder a un público van en la línea, como he indicado, de la visión de la utilidad presente en el Convivio de Dante; pero también de algún que otro humanista como de Leon Battista Alberti, el cual en el prólogo del libro tercero de I libri della famiglia insiste en la obviedad de que, incluso entre los antiguos, el objetivo primordial era el de ser entendidos por todos ${ }^{34}$. Alberti, como es sabido, llevaba a cabo un verdadero manifiesto y defensa del vulgar, insistiendo en la necesidad de utilizar una lengua útil y entendida por todos. En este sentido, permanece sin duda todavía por parte de Palencia y de todos los traductores humanistas castellanos de la época una cierta desconfianza en el vulgar, actitud que no se encuentra ni en Dante ni mucho menos en Alberti, cuya confianza es firme y consciente.

\section{LA TERMINOLOGÍA UTILIZADA: ROMANZAR, TRASLADAR, TRADUZIR}

Pasemos ahora a desgranar otra cuestión que, sin duda, arroja luz sobre el grado de innovación y modernidad en el ámbito de la traducción a lo largo del siglo $\mathrm{XV}$, esto es, a los términos utilizados para designar tal actividad.

Recordemos como premisa que, a diferencia de la concepción medieval que relegaba el traductor a un papel secundario e incluso al anonimato, la traducción entre los humanistas italianos del siglo XV adquirió un papel fundamental y de un valor intelectual de primer orden.

Merece, pues, la pena detenerse en la terminología usada por los autores de la época para referirse a la traducción y sus derivados. Como es sabido, en la Antiguiedad los términos para designar esa labor eran múltiples: vertere, convertere, exprimere, reddere, mutare (Quintiliano, Séneca), interpretari, transferre (poco usual en Cicerón), imitari, aemulari (términos que se relacionaban con el estilo y la retórica griega), translatare (Jerónimo), tradere. Por contra, la acepción de traducere, en el sentido de traducir, no se halla en los autores clásicos, donde indica transportar de una orilla a otra, como vemos en César. Tampoco la Edad Media conoció el término en la acepción moderna y de hecho, como es sabido, traducir, traducción y traductor son vocablos introducidos por Leonardo Bruni hacia $1404^{35}$.

\footnotetext{
${ }^{34}$ Este fragmento del proemio al Libro III representa el razonamiento de Alberti: "E con che ragione arebbono gli antichi scrittori cerco con sí lunga fatica essere utili a tutti e' suoi cittadini scrivendo in lingua da pochi conosciuta? Ma non par luogo qui stenderci in questa materia; forse altrove piú a pieno di questo disputaréno. Benché stimo niuno dotto negarà quanto a me pare qui da credere, che tutti gli antichi scrittori scrivessero in modo che da tutti e' suoi molto voleano essere intesi" (Alberti 1994, p. 163).

${ }^{35}$ Se trata de la carta a Niccolò Niccoli, del 5 septiembre de 1404 (Bruni 2007, Epístola I, 8 , vol. I, p. 15).
} 
La terminología bruniana fue afianzándose en los años siguientes; ya en 1415 en el Cicero novus aparecen -como ha notado Viti ${ }^{36}$ - traductus (traducere), transferre (transtulerat... transtulisse), traductionem (traductio), interpretatione (interpretatio), interpretes (interpres), con predominio de traducere e interpretatio y sus derivados.

Por entonces, traducere, pues, era un neologismo que implicaba la alineación del autor con determinados preceptos o al menos su identificación con el movimiento humanista. En la Península Ibérica ${ }^{37}$ la palabra está atestiguada en diversos autores a partir de los años cuarenta y no casualmente aparece en las traducciones de autores clásicos. Así, por ejemplo, Juan de Mena, en la Summa de la Yliada de Omero $^{38}$, realizada hacia el año 1442, utilizaba diversos términos, entre los cuales traduzir y vulgarizar:

grant don es el que yo trayge si el mi fuerte o rapina no lo viciare y aun la osadía temeraria y atrevida, es a saber, de traduzir y juztgar una tan santa y seráfica obra come la Ylíada de Omero de griego sacada en latín y de latín en nuestra materna y castellana lengua vulgarizar (Mena 1989, p. 334).

Un uso que, por cuanto puede percibirse en las palabras de su prólogo, mucho dista del significado unívoco y, todavía más, de la concepción traductora de un Leonardo Bruni.

Pero Díaz de Toledo fue otro de los precursores al utilizar el término repetidas veces en su traducción del Fedón platónico, recabado de la versión latina hecha por el mismo Bruni: Con grand razón, pues, Leonardo Areçio, docto e sabio honbre en las letras griegas, se trabajó a traduzir en nuestros tienpos del griego en la lengua latina aqueste libro llamado Fedrón ${ }^{39}$.

También Alfonso de Cartagena emplea el término latino en una epístola dirigida a su amigo Fernando Pérez de Guzmán ${ }^{40}$, precisamente a propósito de los méritos de la traducción aristotélica medieval.

Por lo que se refiere al antes mencionado Alfonso de Palencia, en su traducción de las Vidas paralelas de Plutarco alternaba, al igual que otros autores, el uso de los términos romançar (romançear), transladar (o trasladar), volver en latín, pero alguna vez recurre al neologismo traduxir. Con todo, un

\footnotetext{
${ }^{36}$ Véase la introducción de P. Viti en Bruni 2004, pp. 29-30. 2011.

${ }^{37}$ Sobre el término traducir y su historia, véanse: Sánchez 1989; Pöckl 1996-1997; Rubio

${ }^{38}$ Un trabajo sobre esta versión se halla en: Gonzalez, Barrio 1985.

${ }^{39}$ Díaz de Toledo 1993, p. 224.

${ }^{40}$ Pöckl 1996-1997, p. 11; la carta, fechada hacia 1430, se encuentra en Birkenmajer 1922 pp. 162-182.
} 
análisis más atento revela que Palencia usa sólo romançear para sus versiones de la primera época, la Batalla y la Perfección, mientras que traduxir se limita a las traducciones de Plutarco y Josefo: prueba, como hemos dicho anteriormente, del mayor valor que concedía a éstas y de una voluntad de identificarse con el nuevo modo de concebir la dignidad de la traducción inaugurado por Bruni y otros humanistas italianos.

Datos significativos al respecto se recaban de las definiciones dadas en su Universal Vocabulario (Sevilla: Cuatro compañeros, 1490) de interpres, traducere, transcribere, transferre, translatio, translatus:

\begin{tabular}{|c|c|}
\hline U. Voc., Col. I (latín) & U.Voc., Col. II (castellano) \\
\hline $\begin{array}{l}\text { Interpres - interpretis. com. generis: } \\
\text { tertie declinationis: nomen simplex. } \\
\text { nam in usu non est. pres. est interpres } \\
\text { mediator: nuncius: et qui ex altera } \\
\text { in alteram linguam aliquid traducit: } \\
\text { est quoque interpres disertor obscuri. } \\
\text { Virgilius. En. tertio: Troigena interpres } \\
\text { diuum. Interpres auctor. Virgilius. in } \\
\text { Georgicis: Tuque mearum interpres } \\
\text { curarum e conscia iuno. }\end{array}$ & $\begin{array}{l}\text { Interpres.tis. co.g.t.decli. es nombre } \\
\text { simple. Ca pres. no esta en uso. quiere } \\
\text { dezir interprete. mediante: e mensaiero: } \\
\text { y el que traslada algo de una lengua en } \\
\text { otra. es tambien interprete: quien aclara } \\
\text { lo oscuro. Vir. En. } 3 \text {. Troigena interpres } \\
\text { diuum. interpres es auctor segund } \\
\text { Virgilio puso en los Georgicos: Tuque } \\
\text { mearum interpres curarum et conscia } \\
\text { iuno. (I, f. CCXXv) }\end{array}$ \\
\hline $\begin{array}{l}\text { Traducere. detegere: publicare: ad } \\
\text { ulteriora ducere: de lingua in linguam } \\
\text { transferre. }\end{array}$ & $\begin{array}{l}\text { Traducere. descobrir. publicar passar } \\
\text { adelante. transladar de una lengua en } \\
\text { otra. (II, f. CCCCCVv) }\end{array}$ \\
\hline \multicolumn{2}{|l|}{ [No testimonia traductor] } \\
\hline $\begin{array}{l}\text { Transcribere. est quum ius nostrum in } \\
\text { alium transit. et transcripti qui de una } \\
\text { regione in aliam transeunt. quia nomina } \\
\text { dant ut transcribantur. }\end{array}$ & $\begin{array}{l}\text { Transcribere. es quando nuestro derecho } \\
\text { se passa a otri Et son transcriptos los que } \\
\text { de una governaçion passan a otra. Ca } \\
\text { dan sus nombres. para que los escrivan } \\
\text { alla do se passan. (II, f. CCCCCVIv) }\end{array}$ \\
\hline Transferre. mutare. & Transferre. es mudar trasladando. (ibid.) \\
\hline $\begin{array}{l}\text { Translatio. est quum causa ex eo pendet: } \\
\text { qui non videtur agere quod oportet: aut } \\
\text { non apud quos oportet: vel quo tempore: } \\
\text { qua lege: quo crimine: qua pena } \\
\text { oporteat. hec translativa constitutio est } \\
\text { quia indiget translatione. }\end{array}$ & $\begin{array}{l}\text { II Translaçion. es quando la causa } \\
\text { pende del que pareçe non fazer lo que } \\
\text { cumple. o non la trata ante los que } \\
\text { cumple. o en el tiempo devido. o por } \\
\text { la ley complidera. o por qual crimen. o } \\
\text { por qual pena conspliria tratarse. Esta se } \\
\text { dize constituçion traslativa. por que ha } \\
\text { menester translaçion. }(\text { ibid.) }\end{array}$ \\
\hline $\begin{array}{l}\text { Translatus translata translatum. } \\
\text { transductus et transportatus: e } \\
\text { transcriptus de lingua in linguam } \\
\text { mutatus. }\end{array}$ & $\begin{array}{l}\text { Translatus. traduzido. e trasportado. e } \\
\text { trascripto e mudado de una lengua en } \\
\text { otra lengua. (ibid.) }\end{array}$ \\
\hline
\end{tabular}


Así, interpres es sinónimo de mediator / mediante, nuncius / mensaiero y disertor obscuri / quien aclara lo oscuro, y además de corresponder a traductor (escrita idénticamente en vulgar) a el que traslada; traducere también posee un campo semántico amplio siendo sus equivalentes detergere / descobrir, publicare / publicar, ad ulteriora ducere / passar adelante, con el significado específico de lingua in lingua transferre / transladar de una lengua a otra; los términos transcribere y translatio, sorprendentemente, presentan sólo sus significados técnicos en el campo jurídico y burocrático, aunque en el segundo se pone en evidencia su relación con el hecho de la translaçion; los dos restantes se atienen a este campo, así transferre equivale a mutare / mudar trasladando, mientras que translatus-a-um presenta la variedad más significativa, con acepciones aplicables a de lingua in linguam / de una lengua en otra lengua: transductus / traduzido, transportatus / trasportado, transcriptus / trascripto, mutatus / mudado. El término más usado en el Universal Vocabulario es, como vemos, transferre: transfero, transferre, transtuli, translatus (especialmente en infinitivo y participio), siempre como equivalente de trasladar, conjugado también en infinitivo, participio y gerundio (trasladar, trasladado, transladando), mientras que escasean las formas substantivas (sólo un translaçión). Por lo que se refiere al neologismo bruniano, aparece en la forma sustantiva del agente, traductor latino, y en participio (traduzido) pero no en el infinitivo castellano (traducere nunca corresponde a traducir). Así, aun siendo el término transladar el más neutro, los derivados creados a partir de traducere aparecen en casi todas sus formas en la obra lexicográfica de Palencia, completamente asimilados y equivalentes a trasladar.

En los dos últimos prólogos, pues, no aparece romançar y prevalecen, en cambio, transladar y traduxir, con una clara preferencia, en el caso de Plutarco, a favor de este último término, que sirve tanto para designar los traslados de griego a latín como al romance. Así, cuando habla de los traductores italianos que han vertido Plutarco del griego al latín usa siempre trasladar y traduxir, con neto predominio de traduxir:

la translaçión de las Vidas de Plutarco de latín en romançe; (...) de la lengua griega (...) tan provechosa traducçión; tan provechosa translaçión; el bien enseñado Lapo Florentin traduxo treze vidas; Donato Azayolo, florentin, traduxo quatro vidas; Guarino, varon muy mentado en enseñança, traduxo diez e seys vidas; Antonio Tudertino traduxo siete vidas; Leonardo Aretino, principe por entonçes en Ytalia en la doctrina de ambas lenguas, traduxo ocho vidas; Francisco Barbaro, noble veneçiano, traduxo (...); Leonardo Iustiano, noble varón de Veneçia, traduxo dos vidas; Iacobo Angelo de la Scarperia traduxo la vida de César; Francisco Philelpho traduxo las vidas de Galba e de Othón emperadores romanos; Cornelio Nepote avia traduzido la vida de Pomponio Áttico (Plutarco 1491, I, f. 5r). 
Cuando Palencia designa su propia actividad como traductor del latín al romance, hace lo mismo y, al finalizar su prólogo, resume su trabajo como aquesta traduçión. Otro tanto ocurre en los breves prólogos que preceden las vidas, donde también recurre al término traducir. Bastará citar dos ejemplos:

Guarino Veronés escrivió en latín la vida del ylustre philosopho Platón colligida y compuesta por él y el cronista Alfonso de Palençia la traduxo en romançe castellano, después de escriptas y romançadas las Vidas de Plutharco (Plutarco 1491, II, f. 334v).

El evidente cambio de nomenclatura contiene implicaciones que van más allá de una mera relación sinonímica. Mientras que en la obra lexicográfica, aunque incluye el neologismo como un sinónimo de transladar, su presencia no es mayoritaria, ésta domina en los prólogos a las traducciones de autores clásicos, bajo derivados de traducere, claramente preferidos a los de transfero.

\section{CONCLUSIONES}

El grado de innovación y de continuidad en las traducciones peninsulares puede analizarse desde múltiples puntos de vista. El peso que tuvo el humanismo italiano en el desarrollo tanto de las ideas, como de la terminología utilizada o de la misma práctica traductora es un fenómeno que difícilmente podría tratarse en pocas páginas. En este trabajo he pretendido insistir básicamente en tres ideas todavía abiertas a la crítica.

En primer lugar, en el panorama general de la traducción del siglo $\mathrm{XV}$, se percibe una aproximación paulatina a los autores clásicos, en un primer momento con mayor atención a los latinos (Tito Livio, Vegecio, Salustio, Virgilio, Séneca, Cicerón, Valerio Máximo); luego a partir de los años cuarenta, con apertura gradual a los autores griegos (Homero, Platón, Aristóteles, Luciano, Plutarco, Josefo), y un interés creciente por la producción humanística italiana circunscrita en cuanto a temas y autores, entre los que destacan Leonardo Bruni, Poggio Bracciolini, Giannozzo Manetti, Enea Silvio Piccolomini, Guarino Veronese y Donato Acciaiouli.

Todas las traducciones de autores griegos (Aristóteles, Platón, Homero, Luciano, Plutarco y Flavio Josefo) fueron indirectas, a partir de las traducciones latinas elaboradas por los humanistas italianos y no hubo ningún autor que se apartara del sendero común, situación que fue así descrita por Luis Gil: 
Por desgracia, tampoco los intelectuales españoles del siglo XV que intervinieron en el concilio de Basilea, como Alonso de Cartagena, o residieron temporadas en Italia como Juan de Mena y el propio Alonso de Palencia (pese a haberse educado en casa del gran humanista griego Bessarion y a su amistad con Trapezuncio), apreciaron la importancia del griego para la renovación cultural en curso de la que ellos, por otra parte, se sentían animadores y propulsores. Su horizonte humanístico se quedaba en el latín, convencidos quizá de que las traducciones a esta lengua de los autores griegos suplían, cuando se ajustaban al sentido de lo escrito, a los textos originales. Y por ello, aunque se conservan o se tienen noticias de versiones indirectas de obras griegas al castellano, al menos que yo sepa, no se dejan oír en el siglo XV lamentos parecidos a los de Boccaccio por desconocer la lengua griega (Gil 1997, p. 202).

Ello implicó que la apropiación del legado greco-latino, en su conjunto, quizás no diferenciara lo suficiente latinidad de helenismo. Asimismo, las lenguas clásicas tampoco interesaron de la misma manera; el latín saldaba la deuda con la Antigüedad, haciendo que se descuidara el estudio del griego. Esta conclusión, con todo, debería matizarse en algunos casos, como en el de Alfonso de Palencia. Si bien no tuvo la oportunidad de conocer la lengua griega, lo cierto es que sus intereses y los textos elegidos denotan un cambio de intención respecto al pasado, que lo conecta directamente a los humanistas italianos. Los autores traducidos, en concreto Plutarco y Josefo, forman parte del acervo humanista del que se había impregnado en Italia. Aun sin entrar en la calidad de sus versiones, la magnitud de las obras afrontadas constituye un empeño poco común en su tiempo, además de denotar un significativo interés por el legado griego pese a desconocer la lengua.

En segundo lugar, la reflexión sobre la traducción y el método utilizado puede reconstruirse en parte a través de la literatura prologal que los traductores anteponen a sus trabajos, a falta de trabajos sistemáticos como los de Leonardo Bruni. Estas reflexiones conjugan preocupaciones poco originales como el desigual desarrollo del vulgar frente al latín, la distinción de método según la materia o distinciones que esconden la antigua dualidad ad verbum y ad sensum jeronimianos. Otros desasosiegos más complejos van planteándose, como la dificultad en trasladar el ritmo y el estilo del autor traducido, así como el saber encontrar la palabra justa que traiga consigo el significado preciso del original. Por otro lado, a ello se suma una clara vocación divulgativa y pedagógica que parece ir en sintonía con el ideario del humanismo cívico.

En fin, en la terminología utilizada para designar la traducción como actividad intelectual, se evidencia la introducción y el afianzamiento de ciertos neologismos que no son fruto del azar, sino más bien de una tendencia que implica un cambio en la concepción de la figura del traductor. 
Para concluir e insistir en lo anteriormente expuesto, querría retomar las palabras del prólogo que Juan del Encina antepuso a su traducción de las Bucólicas de Virgilio (1496); ya a las puertas del nuevo siglo, resumía así la tarea del traductor:

Suelen aquellos que dan obra a las letras, príncipe muy ecelente, esperimentar sus ingenios en trasladar libros y autores griegos en lengua latina, y assí mesmo los hombres de nuestra nación procuran tomar esperimento de su estudio bolviendo libros de latín en nuestra lengua castellana, y no solamente los hombres de mediano saber, mas aun entre otros varones muy dotos. No rehusó aqueste exercicio Tullo, puesto en la cumbre de todos los ingenios, que bolvió a la lengua latina muchas obras griegas ya perdidas por negligencia de nuestros antecessores, principalmente aquellas muy altas oraciones de Esquines y Demóstenes, cuyo argumento parece, las quales nuevamente trasladó Leonardo Aretino poco tiempo ha, y la Ética de Aristóteles que agora se lee, y otros libros de Platón. Y aun entre los santos dotores no dio pequeña gloria a San Jerónimo la interpretación y tradución de la Biblia, y en este trabajo se ocuparon Aquila y Simaco, Teodoción, Orígenes y Eusebio. Y de los modernos no solamente Leonardo, Filelfo se pusieron a trasladar de una lengua en otra, mas tan bien otros muchos gastaron parte de su tiempo en semejantes exercicios dedicando sus obras a quien su desseo les aconsejava. Y, comoquiera que yo sea tan desseoso del servicio de vuestra alteza como el que más, con aquella fe que a vuestros claríssimos padres, procurando mostrar algo de mi desseo, en las Bucólicas de Virgilio metí la pluma temblando con mucha razón, viendo el valer de vuestro gran merecimiento, $\mathrm{y}$ amonestado por Oracio en el Arte de Poesía, donde dize los escritores aver de elegir materias yguales a las fuerças de sus ingenios (Encina 1978, pp. 225-226).

Juan del Encina es consciente del peso de la traducción concebida entre los italianos como una prueba de ingenio. Estos se atreven a trasladar las obras de la Antigüedad del griego al latín, mientras que los hombres de nuestra nación, incluso los más doctos, se afanan en traducirlas del latín al castellano. La traducción ya es, pues, una actividad intelectual con un alto valor positivo digna de los más claros intelectos. A modo de justificación, se alegan la serie de tópicos, de sobra conocidos, entre los cuales se halla el ejemplo de Cicerón, que versionó dos famosas oraciones de Esquines y Demóstenes, también traducidas por Bruni; como tampoco falta la mención a una figura talismán en el terreno de la traducción medieval, San Jerónimo, y la lista de versiones bíblicas. Pero destacan, sin duda, de entre los modernos, dos nombres: Leonardo Bruni y Francesco Filelfo. Encina emprende, pues, el trabajo con temblorosa pluma, no sólo por el respeto que le infunde el destinatario, sino también porque sabe que la traducción es ahora más que nunca una prueba de alto ingenio. 


\section{BIBLIOGRAFÍA CITADA}

Alberti, Leon Battista (1994), I libri della familia ed. Ruggiero Romano, Alberto Tenenti, Francesco Furlan, Turín, Einaudi.

Allés Torrent, Susanna (2008), Alfonso de Palencia y la traducción de las Vidas de Plutarco (nuevos datos en torno al texto de partida), "Cuadernos de Filología Clásica. Estudios latinos" 28/2, pp. 99-124.

Allés Torrent, Susanna (2010), The Vita Caroli Magni of Donato Acciaiuoli, Translated by Alfonso de Palencia (1491), en Taylor, Barry; Coroleu, Alejandro (eds.), Humanism and Christian Letters in Early Modern Iberia (1480-1630), Newcastle, Cambridge Scholars Publishing, pp. 61-74.

Allés Torrent, Susanna (2013), Il genero biografico degli umanisti e la ricezione nella Penisola Iberica nel Quattrocento: appunti per una revisione, "Quaderns d'Italià" 18, pp. 203-214.

Allés Torrent, Susanna (2014a), Le vite di Omero tradotte da Pellegrino degli Agli, en Musco, Alessandro; Musotto, Giuliana (eds.), Coexistence and Cooperation in the Middle Ages, Palermo, Officina di Studi Medievali.

Allés Torrent, Susanna (2014b), Las Vitae Hannibalis et Scipionis traducidas por Alfonso de Palencia (1491). Introducción, estudio y edición, Barcelona - Madrid, Fédération Internationale des Instituts d'Études Médiévales (Textes et Études du Moyen Âge; 77).

Alvar, Carlos (2001), Una veintena de traductores del siglo XV: prolegómenos a un repertorio, en Martínez Romero, Tomàs; Recio, Roxana (eds.), Essays on medieval translation in the Iberian Peninsula, Castellón, Universitat Jaume I, vol. I, pp. 15-41.

Alvar, Carlos; Lucía Mejías, José Manuel (2003), Repertorio de traductores del siglo XV: Tercera veintena, "Quaderns de filologia. Estudis literaris" 8 , pp. 1-40.

Alvar, Carlos (2010), Traducciones y traductores. Materiales para una historia de la traducción en Castilla durante la Edad Media, Alcalá de Henares, Centro de Estudios Cervantinos (Historia y Literatura; 2).

Avenoza, Gemma (1993), Tradición manuscrita de la versión castellana de los Dichos y Hechos memorables de Valerio Máximo, en Nascimento, Aires A.; Almeida Ribeiro, Cristina (eds.), Actas do IV Congresso da Associaçao Hispanica de Literatura Medieval, Lisboa, Cosmos, vol. III, pp. 43-48.

Bartoli, Lorenzo (2007), La versione castigliana delle Vite di Dante e del Petrarca e la Controversia Alphonsiana: osservazioni filologiche sui rapporti fra Bruni e la Spagna in epoca conciliare, en Muñiz Muñiz, María de las Nieves (ed.), La traduzione della letteratura italiana in Spagna (1300- 
1939). Traduzione e tradizione del testo. Dalla filologia all'informatica. Atti del Primo Convegno Internazionale, Universitat de Barcelona (1316 abril 2005), Barcelona, Franco Cesati, pp. 175-182.

Beardsley, Theodore S. (1970), Hispano-Classical Translations Printed Between 1482 and 1699, Pittsburgh, Pa., Duquesne University Press.

Bertalot, Ludwig (1929-1930), Cencius Romanus und seine Briefe, "Quellen und Forschungen aus Ital. Archiven" 21, pp. 209-255.

Birkenmajer, Alexander (1922), Der Streit des Alonso von Cartagena mit Leonardo Bruni Aretino, "Beiträge zur Geschichte der Philosophie des Mittelalters" 20/5, pp. 129-210.

Botley, Paul (2004), Latin translation in the Renaissance. The Theory and Practice of Leonardo Bruni, Giannozzo Manetti and Desiderius Erasmus, Cambridge, Cambridge University Press.

Bravo García, Antonio (1977), Sobre las traducciones de Plutarco y de Quinto Curcio Rufo hechas por Pier Candido Decembrio y su fortuna en España, "Cuadernos de Filología Clásica" 12, pp. 143-185.

Bruni, Leonardo (2004), Sulla perfetta traduzione, ed. y trad. Paolo Viti, Nápoles, Liguori.

Bruni, Leonardo (2007), Epistolarum libri VIII, recensente Laurentio Mehus (1741), ed. James Hankins, Roma, Edizioni di storia e letteratura.

Cabré, Lluís; Ferrer, Montserrat (eds.) (2012), Cens de traduccions al català medieval fins a 1500 (12 de juny de 2012), URL: http://translatdb. narpan.net/ [consulta: 05/03/2015].

Cammelli, Giuseppe (1941), I dotti bizantini e le origini dell'umanesimo. I. Manuele Crisoloras, II. Giovanni Argiropulo, III. Demetrio Calcondila, Florencia, Vallecchi.

Cartagena, Alfonso de (2003), Pro Marcelo. Edizione critica, studio introduttivo e commento a cura di Andrea Baldissera, Viareggio - Lucca, Mauro Baroni (Agua y peña; 18).

Cartagena, Nelson (2009), La contribución de España a la teoría de la traducción. Introducción al estudio y antología de textos de los siglos $X I V$ y XV, Madrid, Iberoamericana - Frankfurt, Vervuert (Medievalia Hispanica; 13).

Cátedra, Pedro M. (1991), Un aspecto de la difusión del escrito en la Edad Media: la autotraducción al romance, "Atalaya" 2, pp. 67-84.

Conde, Juan Carlos (2006), Ensayo bibliográfico sobre la traducción en la Castilla del siglo XV 1980-2005, "Lemir. Revista de Literatura Española Medieval y del Renacimiento", 10.

Díaz de Toledo, Pedro (1993), Libro llamado Fedron, Plato's Phaedo translated by Pero Díaz de Toledo (MS Madrid, Biblioteca Nacional Vitr. 17, 4), ed. Nicholas G. Round, Londres, Tamesis. 
Encina, Juan del (1978), Traducción de las Bucólicas de Virgilio, ed. Ana María Rambaldo, Madrid, Espasa-Calpe.

García Yebra, Valentín (1994), Traducción: historia y teoría, Madrid, Gredos. Gil, Luis (1997), Panorama social del humanismo español, Madrid, Tecnos, ( $2^{\mathrm{a}}$ ed.).

González Rolán, Tomás; Barrio Vega, María Felisa del (1985), Juan de Mena y su versión de la Ilias latina, "Cuadernos de Filología Clásica" 19, pp. 47-84

González Rolán, Tomás; Moreno Hernández, Ángel; Saquero Suárez-Somonte, Pilar (eds.) (2000), Humanismo y teoría de la traducción en España e Italia en la primera mitad del siglo XV: edición y estudio de la Controversia alphonsiana (Alfonso de Cartagena vs. L. Bruni y P. Candido Decembrio), Madrid, Ediciones Clásicas.

González Rolán, Tomás; Saquero Suárez-Somonte, Pilar (2000), El Axíoco pseudo-platónico traducido e imitado en la Castilla de mediados del siglo XV: edición y estudio de la versión romance de Pedro Díaz de Toledo y de su modelo latino, "Cuadernos de Filología Clásica. Estudios latinos" 19, pp. 157-197.

González Rolán, Tomás; López Fonseca, Antonio (2014), Traducción y elementos paratextuales: los prólogos a las versiones castellanas de textos latinos en el siglo XV. Introducción general, edición y estudio, Madrid, Escolar y Mayo.

Hurtado Albir, Amparo (2007), Traducción y traductología . Introducción a la traductología, Madrid, Cátedra ( $3^{\mathrm{a}}$ ed.).

Jiménez San Cristóbal, Montserrat (2010), El Isagogicon Moralis Disciplinae de Leonardo Bruni y sus versiones castellanas: edición y estudio, Madrid, Universidad Complutense de Madrid (tesis doctoral).

Josefo, Flavio (1492), Guerras de los judíos con los romanos. Contra Apión gramático, trad. Alfonso de Palencia, Sevilla, Meynardo Ungut y Stanislao Polono.

Lafarga, Francisco; Pegenaute, Luis (eds.) (2004), Historia de la Traducción en España, Salamanca, Ambos Mundos.

Lawrance, Jeremy N. H. (1990), Humanism in the Iberian Peninsula, en Goodman, Anthony; MacKay, Angus (eds.), The Impact of Humanism in Western Europe, Londres - Nueva York, Longman Group, pp. 220-258.

Martín Romero, José Julio (2013), La batalla campal de los perros contra los lobos. Una fábula moral de Alfonso de Palencia, Salamanca, Cilengua (Monografías ILT).

Mazzocchi, Giuseppe; Pintacuda, Paolo (2001), La versione castigliana quattrocentesca delle Vite di Dante e del Petrarca di Leonardo Bruni, 
en Rotondi Secchi Tarugi, Luisa (ed.), Rapporti e scambi tra umanesimo italiano ed umanesimo europeo, Milán, Nuovi orizzonti, pp. 439-489.

Mazzocchi, Giuseppe (2007), La Comparazione di Pier Candido Decembrio nella traduzione di Martín de Avila (BNE, mss. 10171), en Muñiz Muñiz, María de las Nieves (ed.), La traduzione della letteratura italiana in Spagna (1300-1939). Traduzione e tradizione del testo. Dalla filologia all'informatica. Atti del Primo Convegno Internazionale, Universitat de Barcelona (13-16 abril 2005), Barcelona, Franco Cesati, pp. 183-206.

Mena, Juan de (1989), Homero romanzado, ed. Miguel Ángel, Pérez Priego, Barcelona, Planeta.

Morales Ortiz, Alicia (2000), Plutarco en España: traducciones de Moralia en el siglo XVI, Murcia, Universidad de Murcia.

Morrás, María (1991), Repertorio de obras, manuscritos y documentos de Alfonso de Cartagena, "Boletín bibliográfico de la Asociación de Literatura Medieval" 5, pp. 213-245.

Morrás, María (1995), Sic et non: en torno a Alfonso de Cartagena y los studia humanitatis, "Euphrosyne" 13, pp. 333-346.

Muñiz Muñiz, María de las Nieves (2004), Le traduzioni spagnole della letteratura italiana all'epoca della Corona d'Aragona: saggio di un catalogo sistematico, en Santoro, Marco (ed.), Le carte aragonesi. Atti del convegno: Ravello, 3-4 ottobre 2002, Pisa - Roma, Istituti editoriali e poligrafici internazionali.

Palencia, Alfonso de (1967), Universal Vocabulario en latín y en romance, ed. Gili Gaya, Samuel, Madrid, Comisión permanente de la Asociación de Academias de la lengua española (ed. facsímil).

Palencia, Alfonso de (1996a), De Perfectione militaris triumphi. La perfección del triunfo, ed. Francisco Javier Durán Barceló, Salamanca, Universidad de Salamanca.

Palencia, Alfonso de (1996b), Espejo de la Cruz. Testo critico e introduzione a cura di Isabella Scoma, Messina, Di Nicolò.

Palencia, Alfonso de (1998), Gesta Hispaniensia: ex annalibus suorum dierum collecta, edición, estudio y notas de Brian Tate, Jeremy Lawrance, Madrid, Real Academia de la Historia.

Piccolomini, Enea Silvio (2003), Estoria muy verdadera de dos amantes. Edizione critica introduzione e note di Ines Ravasini, Roma, Bagatto Libri.

Proyecto Boscán: Catálogo de las traducciones españolas de obras italianas (hasta 1939). http://ub.edu/boscan [consulta: 05/03/2015]

Plutarco (1478), Vitae illustrium virorum, Venecia, Nicolaus Jenson. 
Plutarco (1491), [Vitae illustrium virorum], 2 vols., trad. Alfonso Palencia, Sevilla, Cuatro compañeros alemanes.

Pöckl, Wolfgang (1996-1997), Apuntes para la historia de traducere / traducir, "Hyeronymus Complutensis. El mundo de la traducción" 4-5, pp. $9-15$.

Pujol, Josep (2012), Les traduccions hispàniques de les Heroides d'Ovidi i els Bursarii Ovidianorum de Guillem d'Orléans: una aproximació, en Martínez Gázquez, José; de la Cruz Palma, Óscar; Ferrero Hernández, Cándida (coord.), Estudios de latín medieval hispánico. V Congreso Internacional de Latín Medieval Hispánico. Barcelona, 7-10 de septiembre de 2009, Florencia, SISMEL edizioni del Galluzzo, pp. 245-258.

Recio, Roxana (1991), Alfonso de Madrigal (El Tostado): la traducción como teoría entre lo medieval y lo renacentista, "La Corónica" 19, pp. 112-131.

Recio, Roxana (1995), El concepto de la belleza de Alfonso de Madrigal (El Tostado): la problemática de la traducción literal y libre, en Recio Roxana, (ed.), La traducción en España ss. XIV-XVI, León, Universidad de León, pp. 59-70.

Rossi, Vittorio (1992), Il Quattrocento, Milán, F. Vallardi.

Rubio Tovar, Joaquín (2011), El vocabulario de la traducción en la Edad Media, Alcalá, Universidad de Alcalá.

Ruiz Casanova, José Francisco (2000), Aproximación a una historia de la traducción en España, Madrid, Cátedra.

Rusell, Peter E. (1985), Traducciones y traductores en la Península Ibérica (1400-1550), Bellaterra, Universitat Autònoma de Barcelona.

Sabbadini, Remigio (1920), Il metodo degli umanisti, Florencia, Le Monnier.

Sánchez Manzano, María Asunción (1989), Traducir palabra latina, en Chamosa, José Luis; Santoyo, Julio César; Guzmán González, Trinidad; Rabadán, Rosa (coords.), Fidus Interpres. Actas de las Primeras Jornadas Nacionales de Historia de la Traducción, León, Universidad de León, pp. 156-163.

Santoyo, Julio César (1987), Teoría y crítica de la traducción: antología, Bellaterra, Universitat Autònoma de Barcelona.

Santoyo, Julio César (2004), El siglo XV: un mar de traducciones, en Lafarga, Francisco; Pegenaute, Luís (eds.), Historia de la Traducción en España, Salamanca, Ambos Mundos, pp.144-147.

Santoyo, Julio César (2008), Historia de la traducción: viejos y nuevos apuntes, [León], Universidad de León.

Santoyo, Julio César (2009), La traducción medieval en la Península Ibérica: siglos III-XV, León, Universidad de León. 
Serés, Guillermo (1997), La traducción en Italia y España durante el siglo XV. La Ilíada en romance y su contexto cultural, Salamanca, Universidad de Salamanca.

Vega Cernuda, Miguel Ángel (1994), Bajo el magisterio de San Jerónimo: comentario crítico a la teoría española de la traducción, en Raders, Margit; Martín-Gaitero, Rafael (eds.), Actas de los IV Encuentros Complutenses en torno a la Traducción (Madrid, 24 al 29 de febrero de 1992), Madrid, Editorial Complutense, pp. 61-74.

Weiss, Julian (2013), Vernacular Commentaries and Glosses in Late Medieval Castile, II: Checklist of Classical Texts in Translation, en Beresford, Andrew M.; Haywood, Louise M.; Weiss, Julian (eds.), Medieval Hispanic Studies in Memory of Alan Deyermond, Woodbridge, Tamesis, pp. 237-271.

Wittlin, Curt (1998), El oficio de traductor según Alfonso Tostado de Madrigal en su comentario al prólogo de san Jerónimo a las Crónicas de Eusebio, "Quaderns. Revista de traducció" 2, pp. 9-21.

Fecha de recepción del artículo: septiembre 2014

Fecha de aceptación y versión final: marzo 2015 